\title{
Substituent position-driven reaction pathways in the heterogeneous one-pot reduction/asymmetric hydrogenation of nitro-substituted (E)-2,3-diphenylpropenoic acids over Pd catalyst
}

\author{
György Szőllősia ${ }^{a}$, and Mihály Bartók ${ }^{\mathrm{a}, \mathrm{b}}$ \\ ${ }^{a}$ Stereochemistry Research Group of the Hungarian Academy of Sciences, University of Szeged, \\ 6720 Szeged, Dóm tér 8, Hungary \\ ${ }^{b}$ Department of Organic Chemistry, University of Szeged, 6720 Szeged, Dóm tér 8, Hungary \\ E-mail: szollosi@chem.u-szeged.hu; bartok@,chem.u-szeged.hu
}

Dedicated to Professor Ferenc Fülöp on the occasion of his $60^{\text {th }}$ birthday

\begin{abstract}
The reaction pathway in the heterogeneous enantioselective hydrogenation of nitro-substituted (E)-2,3-diphenylpropenoic acids over Pd catalyst modified by cinchonidine is determined by the position of the substituent. The reaction route was indicated by the $\mathrm{H}_{2}$ consumption curve and enantioselectivity of the final amino acid or 3-phenyl-1,2,3,4-tetrahydro-2-quinolone formed by intramolecular amidation. The obtained enantioselectivities were low with the exception of acids bearing nitro substituent in para position on the 3-phenyl moiety, the latter resulting in good, up to $80 \%$ optical purity. The present study is the first to report the enantioselective heterogeneous catalytic preparation of 1,2,3,4-tetrahydro-2-quinolones and presents an attractive method for obtaining optically enriched 3-(4-aminophenyl)-2-phenylpropionic acids.
\end{abstract}

Keywords: Enantioselective hydrogenation, heterogeneous catalyst, palladium, cinchonidine, unsaturated carboxylic acid, nitro substituent, amino acid, 2-quinolone

\section{Introduction}

Enantioselective catalytic hydrogenations are among the most convenient methods to introduce chirality in organic molecules. ${ }^{1}$ Recent efforts in this field are focused on developing efficient heterogeneous catalytic systems to replace the widely used, sensitive chiral metal complexes. ${ }^{2}$ Among the expedient methods to prepare chiral heterogeneous catalysts is the adsorption of optically pure compounds, so-called modifiers, on metal catalyst surfaces. The most efficient catalysts prepared this way are the tartaric acid-modified $\mathrm{Ni}$ and the cinchona alkaloid-modified $\mathrm{Pt}$ and $\mathrm{Pd}^{3}$ The latter ensured high optical yields in the hydrogenation of prochiral olefins. 
However, the substrate scope is limited to 2-pyrone derivatives and $\alpha, \beta$-unsaturated carboxylic acids. The acid structure was found decisive in obtaining good enantioselection over Pd catalyst modified by cinchonidine (CD). Aliphatic acids were obtained only in up to $70 \%$ enantiomeric excess (ee), ${ }^{4}$ whereas heterocyclic acids in up to $88 \%$ ee. ${ }^{5}$ The best, over $90 \%$ ee, were obtained in the hydrogenation of $(E)$-2,3-diphenylpropenoic acids (see Scheme 1). ${ }^{6}$

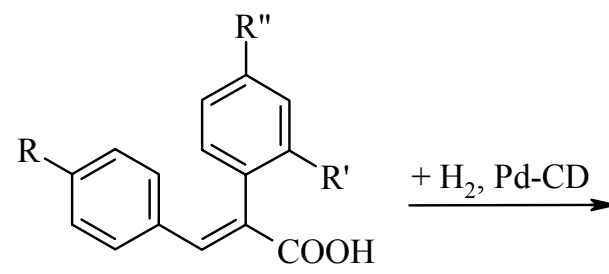

$\mathrm{R}, \mathrm{R}$ ', R": $\mathrm{H}, \mathrm{OCH}_{3}, \mathrm{~F}$

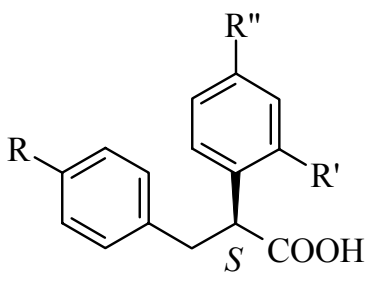

ee $>90 \%$ (up to $96 \%$ )

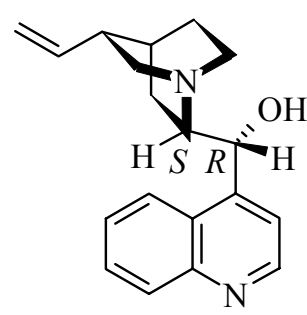

(CD)

Scheme 1. Enantioselective hydrogenation of $(E)$-2,3-diphenylpropenoic acids over Pd catalyst.

Systematic examination showed a remarkable effect of the nature and position of $(E)-2,3$ diphenylpropenoic acid substituents on both the reaction rate and the ee. ${ }^{7}$ Electron donating substituents on the 3-phenyl ring increased the ee except in ortho position. Substituents in the latter position have detrimental influence due to their steric effect. On the contrary, the enantioselection is much less affected by the electronic effect of substituents on the 2-phenyl moiety and ortho substituents have a beneficial influence, probably as a consequence of their steric hindrances. It is known that during hydrogenations the 3-phenyl moiety is adsorbed flatly on the Pd surface in contrast with the tilted arrangement of the 2-phenyl ring. The adsorption mode was demonstrated by differences in the transformation of $(E)$-2,3-diphenylpropenoic acids substituted with chlorine in different positions, i.e. the rate of dehydrochlorination of these acids. $^{8}$

Accordingly, the product distribution and the ee in the enantioselective hydrogenations of (E)-2,3-diphenylpropenoic acids bearing reducible substituents is strongly influenced by the substituent position and its electronic effect. The heterogeneous catalytic reduction of nitroarenes to the corresponding amines is well-known; Pd catalysts being among the most active in this synthetically useful reaction. ${ }^{9}$ In the present study we attempted the preparation of optically enriched amino acids by one-pot reduction - enantioselective hydrogenation of nitro-substituted (E)-2,3-diphenylpropenoic acids over $\mathrm{Pd} / \mathrm{Al}_{2} \mathrm{O}_{3}$ catalyst modified by $\mathrm{CD}$. The influence of the position of the nitro group on the product distribution, $\mathrm{H}_{2}$ up-take rate and ee was examined and substituent position-dependent reaction pathways are suggested. 


\section{Results and Discussion}

The hydrogenation of nitro-substituted (E)-2,3-diphenylpropenoic acids may proceed according to the reaction pathways sketched in Scheme 2. The corresponding amino acids 4 may result either by the initial reduction of the nitro group followed by hydrogenation of the prochiral $\mathrm{C}=\mathrm{C}$ bond or in reverse order by hydrogenation followed by reduction. These steps may proceed parallel with each other leading to mixtures of the intermediate products or concomitant without desorption of the unsaturated amino acid $\mathbf{2}$ or saturated nitro 3 intermediates from the Pd surface. Compounds bearing ortho nitro substituent on the 3-phenyl moiety may be transformed to heterocyclic 3-phenyl-2-quinolone derivatives $\mathbf{5}$ by intramolecular amidation simultaneously with the reduction of the nitro group. ${ }^{10}$

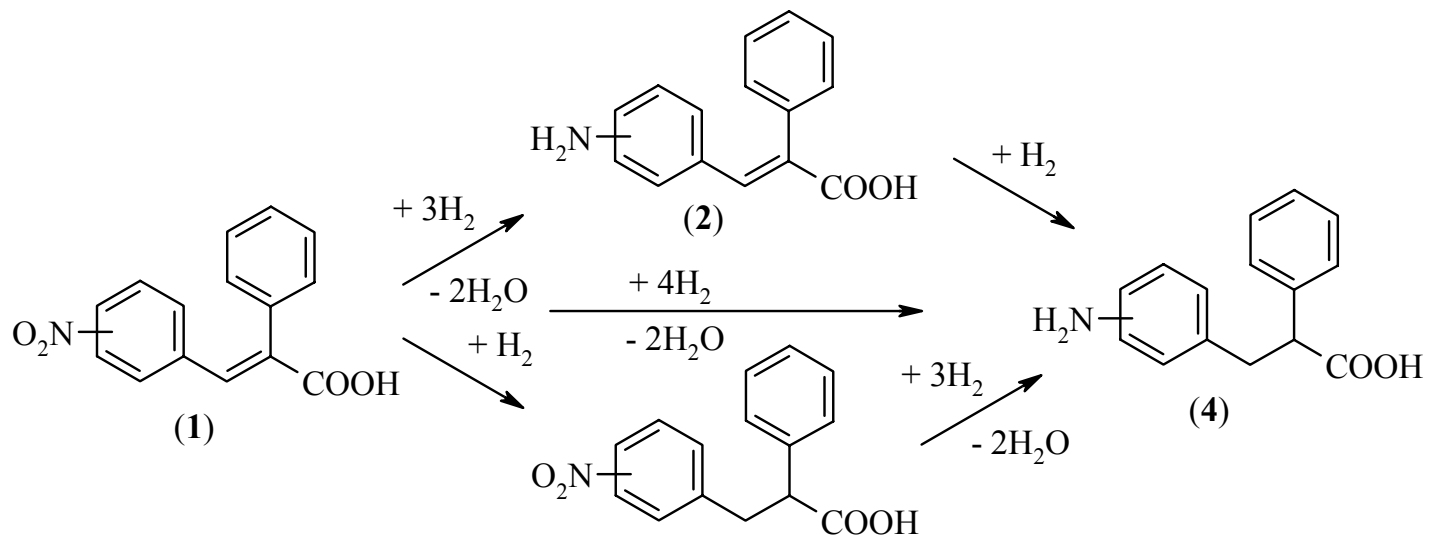

(3)
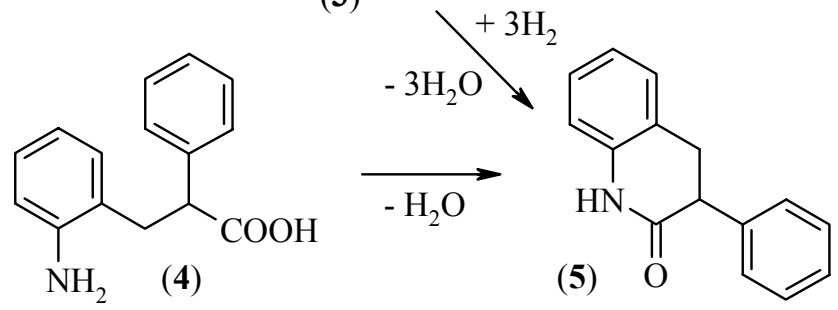

Scheme 2. Possible reaction pathways during the hydrogenation of nitro-substituted $(E)-2,3-$ diphenylpropenoic acids over Pd catalyst.

The influence of the nitro substituent position on the hydrogenation over unmodified Pd and using in-situ modification by CD both in the absence and presence of benzylamine (BA) additive was examined using the acids 1a-1f (Figure 1). Results of hydrogenations are summarized in Table 1 and are compared with those obtained under identical conditions in the hydrogenation of the unsubstituted $(E)$-2,3-diphenylpropenoic acid 1g. ${ }^{6 c}$

According to previous studies substituents with strong electron donating mesomeric effect on the 3-phenyl ring increase the ee ${ }^{6,7}$ It is also known that BA has beneficial effect on both the rate and the ee of the hydrogenation of $1 \mathrm{~g}$ over CD-modified Pd catalysts. The nitro substituent has a 
strong electron withdrawing mesomeric effect, however, by reduction it is transformed to amino group possessing strong electron donating mesomeric effect. Thus, in the hydrogenation of the nitro-substituted acids $\mathbf{1 a}$ and $\mathbf{1 b}$ the ratio between the rates of the nitro group reduction and $\mathrm{C}=\mathrm{C}$ bond hydrogenation is essential in determining the optical purity of the product.

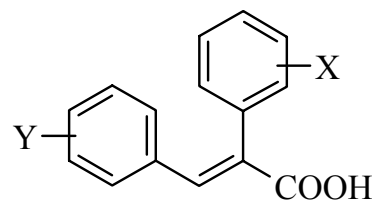
(1a) X: H, Y: 4- $\mathrm{NO}_{2}$
(1b) X: 4-F, $\mathrm{Y}: 4-\mathrm{NO}_{2}$
(1c) $\mathrm{X}: \mathrm{H}, \mathrm{Y}: 3-\mathrm{NO}_{2}$
(1d) $\mathrm{X}: \mathrm{H}, \mathrm{Y}: 2-\mathrm{NO}_{2}$
(1e) $\mathrm{X}: 2-\mathrm{F}, \mathrm{Y}: 2-\mathrm{NO}_{2}$
(1f) $\mathrm{X}: 4-\mathrm{NO}_{2}, \mathrm{Y}: \mathrm{H}$
(1g) $\mathrm{X}: \mathrm{H}, \mathrm{Y}: \mathrm{H}$

Figure 1. Selected (E)-2,3-diphenylpropenoic acid derivatives.

Table 1. Hydrogenation of selected nitro-substituted (E)-2,3-diphenylpropenoic acids 1 over $\mathrm{Pd} / \mathrm{Al}_{2} \mathrm{O}_{3}$ catalyst $^{\mathrm{a}}$

\begin{tabular}{ccccc}
\hline Entry & Substrate & Product $^{\mathrm{b}}$ & $\mathrm{R}_{\mathrm{iH}}\left(\mathrm{mmol} \mathrm{h}^{-1} \mathrm{~g}^{-1}\right)^{\mathrm{c}}$ & ee (\%) ${ }^{\mathrm{d}}$ \\
\hline 1 & $\mathbf{1 a}$ & $\mathbf{4 a}$ & $77 ; 88 ; 84$ & $67 ; 79$ \\
2 & $\mathbf{1 b}$ & $\mathbf{4 b}$ & $102 ; 135 ; 133$ & $71 ; 80$ \\
3 & $\mathbf{1 c}$ & $\mathbf{4 c}$ & $114 ; 126 ; 100$ & $42 ; 52$ \\
4 & $\mathbf{1 d}$ & $\mathbf{5 d}$ & $59 ; 101 ; 89$ & $27 ; 1$ \\
5 & $\mathbf{1 e}$ & $\mathbf{5 e}$ & $77 ; 94 ; 48$ & $37 ; 10$ \\
6 & $\mathbf{1 f}$ & $\mathbf{4 f}$ & $56 ; 39 ; 108$ & $30 ; 43$ \\
$7^{6 \mathrm{c}}$ & $\mathbf{1 g}$ & saturated acid & $51 ; 9 ; 12$ & $70 ; 73$ \\
\hline
\end{tabular}

${ }^{\mathrm{a}}$ Reaction conditions: $25 \mathrm{mg} \mathrm{5 \%} \mathrm{Pd} / \mathrm{Al}_{2} \mathrm{O}_{3}$, solvent: $5 \mathrm{~cm}^{3} \mathrm{DMF}$ with $2.5 \mathrm{vol} \% \mathrm{H}_{2} \mathrm{O}, 0.5 \mathrm{mmol}$ 1, $0.025 \mathrm{mmol} \mathrm{CD}, 0.5 \mathrm{mmol} \mathrm{BA}$ (when used), $0.1 \mathrm{MPa} \mathrm{H}_{2}$, r.t., stirring $1000 \mathrm{rpm}$, hydrogenation time $8 \mathrm{~h}$. ${ }^{\mathrm{b}}$ Conversions $>98 \%$, selectivities of the given products $>95 \%$, by GC. ${ }^{c} \mathrm{R}_{\mathrm{iH}}$ : initial $\mathrm{H}_{2}$ up-take rates of racemic; enantioselective in the absence; presence of BA. ${ }^{\mathrm{d}}$ enantiomeric excesses obtained with; without BA, by GC.

Hydrogenations of $\mathbf{1 a}$ and $\mathbf{1 b}$ in the absence of BA provided slightly lower ee as obtained in the reaction of the corresponding acids lacking the nitro group (1g and ref $^{6 c}$ ). The $\mathrm{R}_{\mathrm{iH}}$ increased by chiral modification in contrast with the significant deceleration resulted in the hydrogenation of 1g. Accordingly, the initial step in the transformation of $\mathbf{1 a}$ and $\mathbf{1 b}$ is predominantly the reduction of the nitro group followed by the enantioselective hydrogenation of the $\mathrm{C}=\mathrm{C}$ bond. 
The lower ee (compare 1a with 1g) showed the slight occurrence of parallel $\mathrm{C}=\mathrm{C}$ and nitro group hydrogenation. The presence of BA decreased the reduction rate of the nitro group leading to decrease in the $\mathrm{R}_{\mathrm{iH}}$ value. Even so the hydrogenation remained much slower, as indicated by the increased ees in the presence of the additive. In consequence, the assumed dominant reaction pathway in the hydrogenation of $\mathbf{1 a}$ and $\mathbf{1 b}$ is illustrated in Scheme 3.

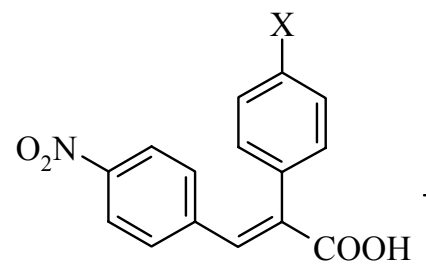

(1a,1b) X: H, F

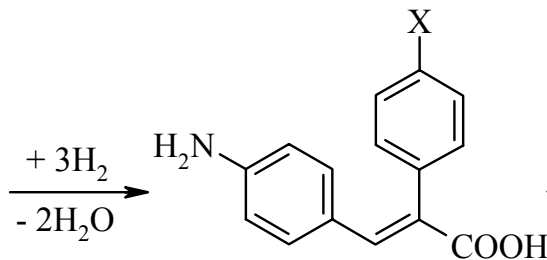

$(\mathbf{2 a}, \mathbf{2 b})$

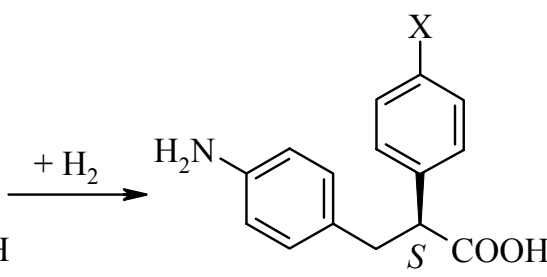

$(\mathbf{4 a}, \mathbf{4 b})$ ee up to $80 \%$

Scheme 3. Hydrogenation pathway of 3-(4-nitrophenyl) derivatives.

In contrast, the hydrogenation of $1 \mathrm{c}$ resulted in low, up to $52 \%$ ee, although, the acid substituted with methoxy group in meta position provided similar ee as the para-substituted compound. $^{7 \mathrm{~b}}$ The high $\mathrm{R}_{\mathrm{iH}}$ indicated facile reduction of the nitro group. From the relatively low ee it is clear that the hydrogenation of $\mathrm{C}=\mathrm{C}$ occurs simultaneously with the former reaction, assumption in line with the faster hydrogenation of the meta-substituted acids as compared with the corresponding para derivatives. ${ }^{6 c}$

The hydrogenation of the ortho-nitro derivatives $1 \mathbf{d}$ and $1 \mathbf{e}$ resulted in quantitative formation of tetrahydro-2-quinolone derivatives in low ees, as expected based on the steric effect of the substituents in this position. ${ }^{6 c, 7 b}$ The relatively high initial rates were in contrast with the very low rates obtained in hydrogenations of the corresponding methoxy substituted derivatives published previously. ${ }^{7 \mathrm{~b}}$ This indicated the predominant initial reduction of the nitro group. The obtained ees showed that the hydrogenation of the prochiral $\mathrm{C}=\mathrm{C}$ bond preceded the intramolecular amidation. Cyclization before the hydrogenation of the $\mathrm{C}=\mathrm{C}$ bond would lead to complete loss of ee, as in the hydrogenation of $\mathbf{1 g}$ methyl ester. ${ }^{11}$ Moreover, the $E$ geometry of the substrates does not allow the cyclization of the unsaturated amino acid intermediate. ${ }^{12}$ Accordingly, the fast reduction of the nitro group preceded the slow hydrogenation of the $\mathrm{C}=\mathrm{C}$ bond necessary for the intramolecular cyclization, as illustrated in Scheme 4.

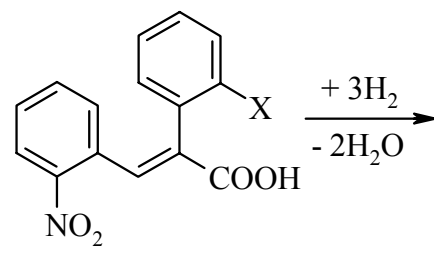

(1d,1e) X: H, F<smiles>[X]c1ccccc1/C(=C\c1ccccc1N)C(=O)O</smiles>

$(\mathbf{2 d}, \mathbf{2 e})$

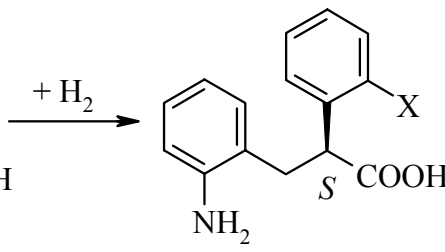

$(\mathbf{4 d}, \mathbf{4 e})$

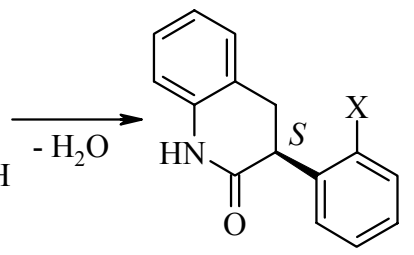

(5d,5e) ee $27 \%, 37 \%$

Scheme 4. Hydrogenation pathway of 3-(2-nitrophenyl) derivatives. 
The hydrogenation of the nitro derivative substituted on the 2-phenyl moiety in para position (1f) resulted in disappointingly low ee. This compound showed the usual trend in the alteration of the $\mathrm{R}_{\mathrm{iH}}$, i.e. decrease by chiral modification and increase in presence of BA. ${ }^{6,7}$ This trend indicated the predominant hydrogenation of the $\mathrm{C}=\mathrm{C}$ bond at the early stage of the reaction. Similarly, the increase in the ee by addition of BA also pointed to this conclusion. However, the low ee is surprising in view of the much weaker electronic effect of substituents on the 2-phenyl ring as compared with those on the 3-phenyl moiety. Thus, the presence of the nitro group on the 2-phenyl ring hindered the efficient interaction of the acid with $\mathrm{CD}$ on the surface. The results obtained in the hydrogenation of this compound indicated that the reaction takes place predominantly according to the pathway shown in Scheme 5.<smiles>O=C(O)/C(=C/c1ccccc1)c1ccc([N+](=O)[O-])cc1</smiles>

(1f)

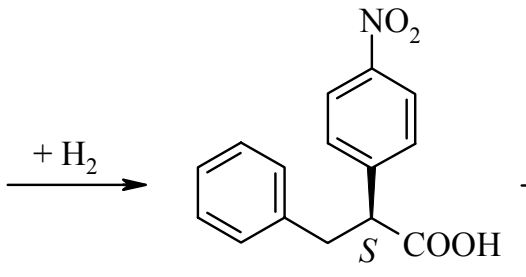

(3f)

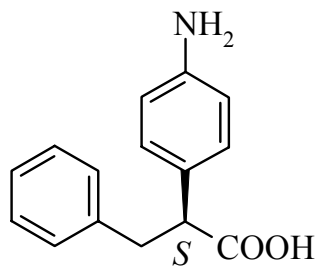

(4f) ee up to $43 \%$

Scheme 5. Hydrogenation pathway of 2-(4-nitrophenyl) derivatives.

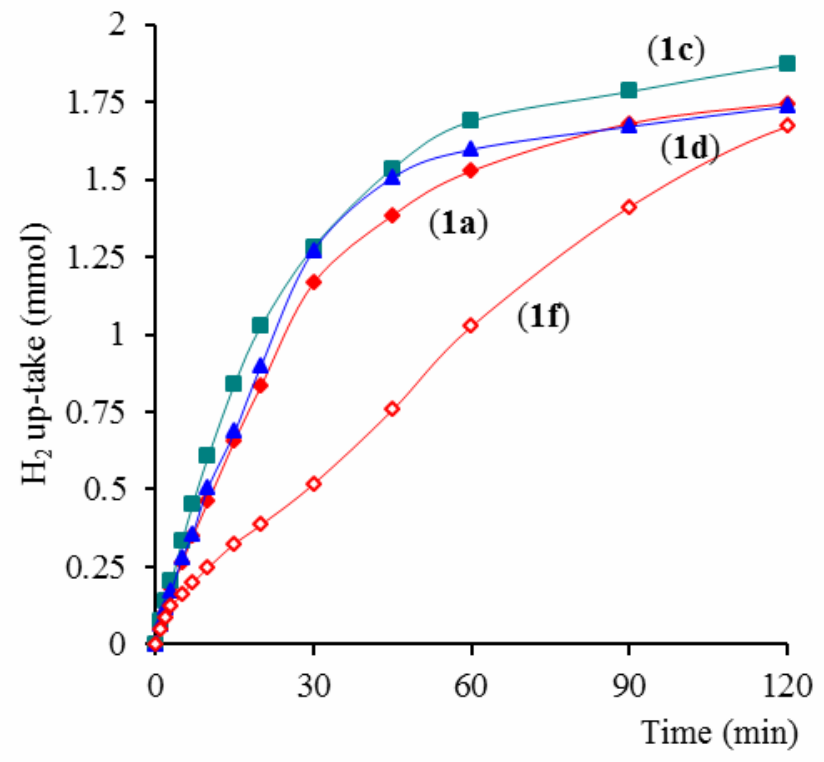

Figure 2. $\mathrm{H}_{2}$ consumption curves of selected $(E)$-2,3-diphenylpropenoic acid derivatives over $\mathrm{Pd} / \mathrm{Al}_{2} \mathrm{O}_{3}$ modified by $\mathrm{CD}$ (for reaction conditions see Table 1 ).

The reaction pathways deduced from results obtained in the hydrogenation of the nitrosubstituted acids are verified by the $\mathrm{H}_{2}$ consumption curves shown in Figure 2. The curves 
confirmed the rapid reduction of the nitro group in 1a, 1c and 1d with the simultaneous hydrogenation of $\mathrm{C}=\mathrm{C}$ bond in the reaction of 1c, or with predominant consecutive hydrogenation in the transformation of the other two acids. The latter was shown by the drop in the $\mathrm{H}_{2}$ consumption at $\sim 1.5 \mathrm{mmol} \mathrm{H}_{2}$ up-take. The initial hydrogenation of the $\mathrm{C}=\mathrm{C}$ bond in the reaction of $\mathbf{1 f}$ is clearly indicated by the inflection point in the $\mathrm{H}_{2}$ up-take curve at $\sim 0.5 \mathrm{mmol}$ consumption. Accordingly, the reduction of the nitro group in this compound occurs by desorption and readsorption of the nitro-substituted diphenylpropionic acid, supporting the tilted arrangement of the 2-phenyl ring on the Pd surface during hydrogenation, which can not permit the simultaneous transformation of both reactive groups in $\mathbf{1 f}$.

\section{Conclusions}

The enantioselective hydrogenation of nitro-substituted $(E)$-2,3-diphenylpropenoic acids was studied over $\mathrm{Pd}$ catalyst modified by cinchonidine. The product distributions, the $\mathrm{H}_{2}$ consumption rates and the optical purities of the products were defined by the position of the nitro substituent. Hydrogenations of the acids resulted in close to quantitative formation of the corresponding amino-substituted saturated acids, except the 3-(2-nitrophenyl) derivatives, which by intramolecular amidation provided the corresponding 3-phenyl-1,2,3,4-tetrahydro-2quinolones. The reaction pathways were found to differ in the hydrogenations of acids substituted in various positions. The most striking difference was found in the reaction of compounds bearing the nitro group on the 3-phenyl moiety as compared with that substituted on the 2-phenyl ring, due to dissimilar arrangements of the two phenyl rings on the catalyst surface during the hydrogenations. Our study showed that the procedure used is applicable heterogeneous catalytic method for the enantioselective preparation of 3-phenyl-1,2,3,4tetrahydro-2-quinolones, yet in low optical purities. Moreover, the amino acids resulted by the hydrogenation of acids substituted on the 3-phenyl ring in para position were obtained in good, up to $80 \%$ enantioselectivities. Considering that these amino acids are useful intermediates in the preparation of various 2,3-diphenylpropionic acid derivatives of pharmaceutical importance, ${ }^{13}$ the reported heterogeneous catalytic method deserves further attention.

\section{Experimental Section}

General. The commercial $5 \% \mathrm{Pd} / \mathrm{Al}_{2} \mathrm{O}_{3}$ (Engelhard, 40692) was pretreated in $\mathrm{H}_{2}$ flow at $523 \mathrm{~K}$

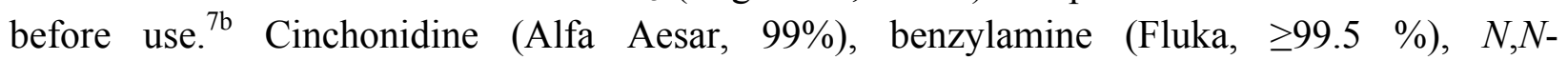
dimethylformamide (DMF, Scharlau, Multisolvent grade) and $\mathrm{H}_{2}$ gas (Linde AG, $99.999 \%$ ) were used as received. (E)-2,3-diphenylpropenoic acid 1g (Aldrich, $\geq 97 \%$ ) was purified by crystallization in acetone-water. The benzaldehyde and phenylacetic acid derivatives, acetic 
anhydride, triethylamine, reagents and solvents were purchased from Aldrich and used without purification.

NMR spectra were recorded on Bruker Avance DRX 500 NMR instrument in $\left(\mathrm{CD}_{3}\right)_{2} \mathrm{SO}$ or $\mathrm{CDCl}_{3}$ using $\left(\mathrm{CH}_{3}\right)_{4} \mathrm{Si}$ as internal standard. The melting points are uncorrected. The isomer distribution of the crude $(E)$-2,3-diphenylpropenoic acid derivatives and their purity were monitored by analytical TLC (Fluka Silica gel/TLC cards, eluent hexane/acetone) and GC-MSD analysis (methyl ester): Agilent Techn. 6890N GC-5973 inert MSD, column: HP-1MS $60 \mathrm{~m} \times$ $0.25 \mathrm{~mm}$, oven temperature: $373 \mathrm{~K} 10 \mathrm{~min}, 10 \mathrm{~K} / \mathrm{min}$ to $473 \mathrm{~K}$ and $473 \mathrm{~K} 100 \mathrm{~min}$, head pressure 21 psi. Enantiomeric separation of products was carried out by gas-chromatography (GC) using YL6100 GC - FID equipped with a chiral capillary column: Cyclosil-B (30 m × 0.25 mm, J \& W Sci. Inc.,). Elemental analyses were performed using a Perkin-Elmer 2400 CHNS elemental analyzer. Optical rotation measurements were carried out using Polamat A polarimeter in methanol, $c 1, l 0.5, \lambda 246 \mathrm{~nm}$.

\section{Preparation of the nitro-substituted $(E)$-2,3-diphenylpropenoic acid derivatives}

The substituted $(E)$-2,3-diphenylpropenoic acids were prepared by Perkin condensation using the corresponding benzaldehyde and phenylacetic acid derivatives. ${ }^{6 \mathrm{c}}$ A stirred mixture of arylacetic acid $(40 \mathrm{mmol})$ and aromatic aldehyde $(40 \mathrm{mmol})$ in $4 \mathrm{~cm}^{3}$ triethylamine and $8 \mathrm{~cm}^{3}$ acetic anhydride was refluxed for 3-6 hours. The solution was cooled to room temperature, $9 \mathrm{~cm}^{3}$ conc. $\mathrm{HCl}$ and $30-40 \mathrm{~cm}^{3}$ water was added, the precipitate was filtered and washed with cold water. The dried solid was dissolved in $1 \% \mathrm{NaOH}$ aqueous solution, the alkaline solution was stirred with charcoal at room temperature and filtered. For separation of the acid isomers the alkaline solution was gradually acidified with $1 / 1 \mathrm{cc}$. $\mathrm{HCl} /$ water solution. The fraction with the highest $E$ isomer content was purified by several crystallizations in ethanol/water up to $98 \%$ purities. Purities of crystallized products were monitored by analytical TLC, ${ }^{1} \mathrm{H}$ - and ${ }^{13} \mathrm{C}-\mathrm{NMR}$ spectroscopy and GC-MSD analysis (as methyl esters prepared using $\mathrm{CH}_{2} \mathrm{~N}_{2}$ ethereal solution). (E)-2-phenyl-3-(4-nitrophenyl)propenoic acid 1a, yield 55\%, mp: 214-217 C, CAS No: $19319-$ 30-3; (E)-2-phenyl-3-(3-nitrophenyl)propenoic acid 1c, yield: $48 \%$, mp: $184-186^{\circ} \mathrm{C}$, CAS No: 22161-41-7; (E)-2-phenyl-3-(2-nitrophenyl)propenoic acid 1d, yield: $54 \%$, mp: 197-200 ${ }^{\circ} \mathrm{C}$, CAS No: 19319-35-8; (E)-2-(4-nitrophenyl)-3-phenylpropenoic acid 1f, yield: 52 \%, mp: $227-$ $228^{\circ} \mathrm{C}$, CAS No: 20432-24-0 are known compounds and their physicochemical data were in good agreement with literature data. ${ }^{14}$

(E)-2-(4-Fluorophenyl)-3-(4-nitrophenyl)propenoic acid (1b). Yield: $50 \%, \mathrm{C}_{15} \mathrm{H}_{10} \mathrm{FNO}_{4}$, Elemental analysis calc.: C 62.7\%, H 3.5\%, N 4.9\%, found: C 63.2\%, H 3.5\%, N 4.8\%; ${ }^{1} \mathrm{H} \mathrm{NMR}$ (500 MHz): $8.06(2 \mathrm{H}, \mathrm{d}, J=8.5 \mathrm{~Hz}, \mathrm{ArH}), 7.85(1 \mathrm{H}, \mathrm{s},=\mathrm{CH}), 7.30(2 \mathrm{H}, \mathrm{d}, J=8.5 \mathrm{~Hz}, \mathrm{ArH})$, 7.17-7.23 (4H, m, ArH); ${ }^{13} \mathrm{C}$ NMR (125 MHz): $167.6(\underline{C O O H}), 161.7(\mathrm{~d}, J=244.8 \mathrm{~Hz}, \underline{C}-\mathrm{F})$, 146.7, 141.3, $136.6(\mathrm{H} \underline{C}=), 136.0,131.6(\mathrm{~d}, J=6.1 \mathrm{~Hz}), 131.4,130.8,123.2,115.4(\mathrm{~d}, J=21.4$ $\mathrm{Hz}$ ); mp: $242-243^{\circ} \mathrm{C}$; GC-MSD, $1 \mathbf{b}$ methyl ester, $m / z$ (rel. int.): 301( $\left.\mathrm{M}^{+}, 100\right), 242(32), 196(35)$, 183(21), 166(66), $120(11)$. 
(E)-2-(2-Fluorophenyl)-3-(2-nitrophenyl)propenoic acid (1e). Yield: $46 \%, \mathrm{C}_{15} \mathrm{H}_{10} \mathrm{FNO}_{4}$, Elemental analysis calc.: C 62.7\%, H 3.5\%, N 4.9\%, found: C 63.0\%, H 3.5\%, N 4.8\%; ${ }^{1} \mathrm{H}$ NMR $(500 \mathrm{MHz}): 8.17(1 \mathrm{H}, \mathrm{s},=\mathrm{CH}), 8.10(1 \mathrm{H}, \mathrm{m}, J=3.5,6.0 \mathrm{~Hz}, \mathrm{ArH}), 7.47-7.52(2 \mathrm{H}, \mathrm{m}, J=3.5$, $6.0 \mathrm{~Hz}, \mathrm{ArH}), 7.29(1 \mathrm{H}, \mathrm{m}, J=3.0,5.5,9.1,11.1 \mathrm{~Hz}, \mathrm{ArH}), 7.10(1 \mathrm{H}, \mathrm{m}, J=9.1,9.6 \mathrm{~Hz}, \mathrm{ArH})$, 7.02-7.06 (2H, m, $J=3.0,3.5 \mathrm{~Hz}, \mathrm{ArH}), 7.00(1 \mathrm{H}, \mathrm{m}, J=3.5,5.5 \mathrm{~Hz}, \mathrm{ArH}) ;{ }^{13} \mathrm{C}$ NMR $(125$ MHz): $166.7(\underline{C O O H}), 159.5(\mathrm{~d}, J=244.8 \mathrm{~Hz}, \underline{C}-\mathrm{F}), 147.3,139.1(\mathrm{H} \underline{C}=), 133.5,131.7,130.8$, 130.6, 130.1 (d, $J=9.2 \mathrm{~Hz}), 129.5,124.4,123.9,122.5$ (d, $J=18.4 \mathrm{~Hz}), 115.0$ (d, $J=21.4 \mathrm{~Hz})$; mp: $210-215^{\circ} \mathrm{C}$; GC-MSD, 1e methyl ester, $m / z$ (rel. int.): 301( $\left.\mathrm{M}^{+}, 1\right), 256(12), 242(23), 224(8)$, 214(12), 194(11), 183(25), 123(100), 119(30), 92(23).

\section{Hydrogenation procedure}

The hydrogenations were carried out in glass hydrogenation apparatus under atmospheric $\mathrm{H}_{2}$ pressure and room temperature using magnetic stirring. The initial hydrogenation rates $\left(\mathrm{R}_{\mathrm{iH}}\right)$ were determined from the $\mathrm{H}_{2}$ up-take curves at $0.05-0.20 \mathrm{mmol}_{2}$ consumption. In a typical run $0.025 \mathrm{~g}$ catalyst and $3 \mathrm{~cm}^{3}$ DMF containing $2.5 \mathrm{vol} \% \mathrm{H}_{2} \mathrm{O}$ were introduced into reactor, the apparatus was flushed with $\mathrm{H}_{2}$, the catalyst was pretreated in-situ by stirring for $0.5 \mathrm{~h}$ under $\mathrm{H}_{2}$ followed by addition of $0.025 \mathrm{mmol} \mathrm{CD}$ (except in the racemic hydrogenations), $0.5 \mathrm{mmol}$ unsaturated acid, $0.5 \mathrm{mmol} \mathrm{BA}$ (when used) and another $2 \mathrm{~cm}^{3}$ solvent. The system was flushed and filled with $\mathrm{H}_{2}$ and the slurry was stirred $(1000 \mathrm{rpm})$ for 8 hours. After this time $5 \mathrm{~cm}^{3}$ methanol was added, the catalyst was filtered, washed with $5 \mathrm{~cm}^{3}$ methanol and the solvent was evaporated under reduced pressure. Portions of products were treated with $\mathrm{CH}_{2} \mathrm{~N}_{2}$ ethereal solution. The products were identified by GC-MSD and conversions were determined by GCFID analysis. Enantiomeric excesses (ee \%) were determined by GC-FID analysis using chiral capillary column. For enantiomeric separation some of the methyl esters or 2-quinolones were further transformed without altering the configuration of the chiral centers: the primary amines in $\mathrm{N}$-acetyl or/and $\mathrm{N}$-trifluoroacetyl derivatives (Scheme 6); the tetrahydro-2-quinolone derivatives in $N$-ethyloxycarbonyl compounds followed by ring opening of the $N$-protected lactams in methanol to the $N$-protected amino acid methyl esters (Scheme 7). These derivatives were identified by GC-MSD analysis. The enantiomeric excesses (ee \%) were calculated with the formulae ee $\%=100 \times|[S]-[R]| /([S]+[R])$, where $[S]$ and $[R]$ are the concentrations of the derivatized product enantiomers. The absolute configuration of the excess enantiomer of the unsubstituted 2,3-diphenylpropionic acid was assigned in previous studies to be $S$. Optical rotation measurements using the crude products showed excess of the dextrorotatory enantiomers in each reaction, which are assumed to be the $S$ enantiomers. 
<smiles>COC(=O)C(Cc1ccc(N)cc1)C(Cc1ccccc1)c1ccccc1</smiles>

Scheme 6. Derivatization of the saturated amino acids for enantiomeric separation.

(5)

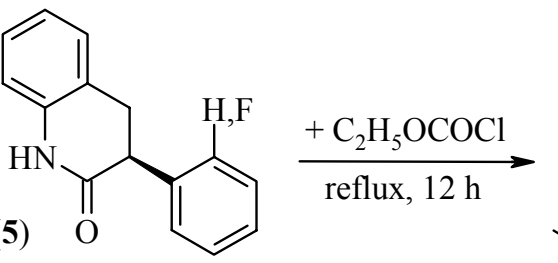<smiles>CCOC(=O)N1C(=O)C(c2ccccc2F)Cc2ccccc21</smiles><smiles>CCOC(=O)Nc1ccccc1CC(C(C)=O)c1ccccc1F</smiles>

Scheme 7. Transformation of tetrahydroquinolone derivatives for enantiomeric separation.

Results of the GC-MSD analysis of the crude products

2-Phenyl-3-(4-aminophenyl)propionic acid (4a). ${ }^{15}$ CAS No: 6318-46-3, methyl ester, $m / z($ rel. int.): 255( $\left.\mathrm{M}^{+}, 6\right), 106(100), 77(5)$; $N$-acetyl-4a methyl ester, $m / z\left(\right.$ rel. int.): 297( $\left.\mathrm{M}^{+}, 11\right), 238(8)$, 148(100), 106(95), 77(6), 43(8); $N$-trifluoroacetyl-4a methyl ester, $m / z$ (rel. int.): 351( $\left.\mathrm{M}^{+}, 10\right)$, 292(3), 202(100), 132(6), 107(14).

2-(4-Fluorophenyl)-3-(4-aminophenyl)propionic acid (4b). Methyl ester, $m / z$ (rel. int.): 273( $\left.\mathrm{M}^{+}, 6\right), 214$ (4), 106(100), 77(5); $N$-acetyl-4b methyl ester, $m / z\left(\right.$ rel. int.): $315\left(\mathrm{M}^{+}, 8\right), 256(9)$, 148(100), 106(97), 43(9).

2-Phenyl-3-(3-aminophenyl)propionic acid (4c). ${ }^{15}$ CAS No: 94252-06-9, methyl ester, $m / z$ (rel. int.): 255( $\left.\mathrm{M}^{+}, 100\right), 233(16), 196(65), 118(17), 106(98), 91(17), 77(30)$.

3-Phenyl-1,2,3,4-tetrahydro-2-quinolone (5d). ${ }^{15}$ CAS No: 1022-66-8, $m / z$ (rel. int.): $223\left(\mathrm{M}^{+}\right.$, 100), 194(67), 179(11), 132(18), 118(26), 91(21); $N$-ethyloxycarbonyl-5d, $m / z$ (rel. int.): 295(M ${ }^{+}$, 62), 222(37), 204(25), 194(100), 179(19), 146(32), 132(25), 118(22), 91(30); 2-phenyl-3-(Nethyloxycarbonyl-2-aminophenyl)propionic acid methyl ester: $m / z\left(\right.$ rel. int.): 327( $\left.\mathrm{M}^{+}, 6\right), 249(10)$, 222(22), 194(17), 178(23), 150(10), 132(100).

2-(4-Nitrophenyl)-3-phenylpropionic acid (4f). ${ }^{15}$ CAS No: 167372-09-0, methyl ester, $m / z$ (rel. int.): 255( $\left.\mathrm{M}^{+}, 17\right), 196(12), 164(100), 136(24), 121(7), 91(8) ; N$-acetyl-4f methyl ester, $m / z($ rel. int.): 297( $\left.\mathrm{M}^{+}, 29\right), 238$ (15), 206(100), 164(98), 136(17), 91(20), 43(10).

Characterization of the product resulted in the hydrogenation of $1 \mathbf{e}$ purified by crystallization 3-(2-Fluorophenyl)-1,2,3,4-tetrahydro-2-quinolone (5e). Yield 95\%, $\mathrm{C}_{15} \mathrm{H}_{12} \mathrm{FNO}$, Elemental analysis calc.: C 74.7\%, H 5.0\%, N 5.8\%, found: C 75.0\%, H 5.2\%, N 5.6\%; ${ }^{1} \mathrm{H} \mathrm{NMR}\left(\mathrm{CDCl}_{3}\right.$, 
$500 \mathrm{MHz}): 8.49(1 \mathrm{H}, \mathrm{s}, \mathrm{NH}), 7.07-7.30(\mathrm{~m}, 6 \mathrm{H}, \mathrm{ArH}), 6.99(1 \mathrm{H}, \mathrm{tr}, J=7.5 \mathrm{~Hz}, \mathrm{ArH}), 6.79(1 \mathrm{H}$, $\mathrm{d}, J=8.1 \mathrm{~Hz}, \mathrm{ArH}), 4.11\left(1 \mathrm{H}, \mathrm{dd}, J=6.5,12.6 \mathrm{~Hz}, \mathrm{CH}_{2}\right), 3.31(1 \mathrm{H}, \mathrm{dd}, J=12.6,15.6 \mathrm{~Hz}$, $\mathrm{PhCH}), 3.12\left(1 \mathrm{H}, \mathrm{dd}, J=6.5,15.6 \mathrm{~Hz}, \mathrm{CH}_{2}\right) ;{ }^{13} \mathrm{C} \mathrm{NMR}\left(\mathrm{CDCl}_{3}, 125 \mathrm{MHz}\right)$ : $171.4(\underline{C O N H})$, $161.4(\mathrm{~d}, J=244.8 \mathrm{~Hz}, \underline{C}-\mathrm{F}), 137.5,130.2,129.5$ (d, $J=6.1 \mathrm{~Hz}), 128.4,128.2,126.1(\mathrm{~d}, J=15.3$ $\mathrm{Hz}), 124.7,123.8,123.6,116.1(\mathrm{~d}, J=24.5 \mathrm{~Hz}), 115.7,41.6(\underline{\mathrm{C}} \mathrm{H}-\mathrm{PhF}), 33.3\left(\underline{C H}_{2}-\mathrm{CH}\right) ; \mathrm{mp}:$ 190-192 ${ }^{\circ}$; GC-MSD, $m / z$ (rel. int.): 241( $\left.{ }^{+}, 100\right), 212(57), 132(35), 118(15), 109(10)$; $N-$ ethyloxycarbonyl-5e, $m / z$ (rel. int.): 313( $\left.\mathrm{M}^{+}, 54\right), 241(43), 222(18), 212(100), 146(29), 132(54)$, 118(18), 109(20); 2-(2-fluorophenyl)-3-(N-ethyloxycarbonyl-2-aminophenyl)propionic acid methyl ester: $m / z$ (rel. int.): 345(M+17), 239(43), 220(42), 178(29), 150(14), 132(100).

\section{Acknowledgements}

Financial support by the Hungarian National Science Foundation (OTKA Grant K 72065) is highly appreciated. The work was supported by the János Bolyai Research Scholarship of the Hungarian Academy of Sciences (Gy. Szőllősi).

\section{References}

1. (a) Ohkuma, T.; Kitamura, M.; Noyori, R. in Catalytic Asymmetric Synthesis, 2nd Edn.; Ojima, I. Ed.; Wiley-VCH: New York, 2000; Chap. 1, pp 1-110. (b) Blaser, H.-U.; Malan, C.; Pugin, B.; Spindler, F.; Steiner, H.; Studer, M. Adv. Synth. Catal. 2003, 345, 103.

2. (a) De Vos, D. E.; Vankelecom, I. F. J.; Jacobs, P. A. Eds. Chiral Catalyst Immobilization and Recycling; Wiley-VCH: Weinheim; 2000. (b) Heitbaum, M.; Glorius, F.; Escher, I. Angew. Chem. Int. Ed. 2006, 45, 4732. (c) Ding, K.; Uozumi, Y. Eds. Handbook of Asymmetric Heterogeneous Catalysis; Wiley-VCH: Weinheim, 2008.

3. (a) Studer, M.; Blaser, H.-U.; Exner, C. Adv. Synth. Catal. 2003, 345, 45. (b) Murzin, D. Yu.; Mäki-Arvela, P.; Toukoniitty, E.; Salmi, T. Catal. Rev. Sci. Eng. 2005, 47, 175. (c) Osawa, T.; Harada, T.; Takayasu, O. Curr. Org. Chem. 2006, 10, 1513. (d) Bartók, M. Curr. Org. Chem. 2006, 10, 1533. (e) Mallat, T.; Orglmeister, E.; Baiker, A. Chem. Rev. 2007, 107, 4863. (f) Margitfalvi, J. L.; Tálas, E. In Catalysis; Spivey, J. J.; Dooley, K. M. Eds.; RSC Publ.: Cambridge, 2010; Vol. 22, pp 144-278.

4. (a) Borszeky, K.; Mallat, T.; Baiker, A. Catal. Lett. 1996, 41, 199. (b) Kun, I.; Török, B.; Felföldi, K.; Bartók, M. Appl. Catal. A: Gen. 2000, 203, 71. (c) Szőllősi, Gy.; Niwa, S.; Hanaoka, T.; Mizukami, F. J. Mol. Catal. A: Chem. 2005, 230, 91. (d) Szőllősi, Gy.; Hanaoka, T.; Niwa, S.; Mizukami, F.; Bartók, M. J. Catal. 2005, 231, 480. (e) Szőllősi, Gy.; Balázsik, K.; Bartók, M. Appl. Catal. A: Gen. 2007, 319, 193. (f) Szőllősi, Gy.; Makra, Zs.; Bartók, M. React. Kinet. Catal. Lett. 2009, 96, 319. (g) Makra, Zs.; Szőllősi, Gy.; Bartók, M. Catal. Today 2011, doi: 10.1016/j.cattod.2011.07.034. 
5. (a) Szőllősi, Gy.; Szőri, K.; Bartók, M. J. Catal. 2008, 256, 349. (b) Szőri, K.; Szőllősi, Gy.; Bartók, M. New J. Chem. 2008, 32, 1354.

6. (a) Nitta, Y. Chem. Lett. 1999, 28, 635. (b) Nitta, Y.; Watanabe, J.; Okuyama, T.; Sugimura, T. J. Catal. 2005, 236, 164. (c) Szőllősi, Gy.; Hermán, B.; Felföldi, K.; Fülöp, F.; Bartók, M. Adv. Synth. Catal. 2008, 350, 2804. (d) Kubota, T.; Kubota, H.; Kubota, T.; Moriyasu, E.; Uchida, T.; Nitta, Y.; Sugimura, T.; Okamoto, Y. Catal. Lett. 2009, 129, 387. (e) Szőllősi, Gy.; Hermán, B.; Fülöp, F.; Bartók, M. J. Catal. 2010, 276, 259.

7. (a) Sugimura, T.; Watanabe, J.; Okuyama, T.; Nitta, Y. Tetrahedron: Asymmetry 2005, 16, 1573. (b) Szőllősi, Gy.; Hermán, B.; Felföldi, K.; Fülöp, F.; Bartók, M. J. Mol. Catal. A: Chem. 2008, 290, 54. (c) Sugimura, T.; Uchida, T.; Watanabe, J.; Kubota, T.; Okamoto, Y.; Misaki, T.; Okuyama, T. J. Catal. 2009, 262, 57.

8. Szőllősi, Gy.; Hermán, B.; Szabados, E.; Fülöp, F.; Bartók, M. J. Mol. Catal. A: Chem. 2010, 333, 28.

9. (a) Nishimura, S. Handbook of Heterogeneous Catalytic Hydrogenation for Organic Synthesis; Wiley: New York, 2001; Chap. 9, pp 315-386. (b) Blaser, H. U.; Siegrist, U.; Steiner H.; Studer, M. In Fine Chemicals through Heterogeneous Catalysis, Sheldon, R. A.; van Bekkum, H. Eds.; Wiley-VCH: Weinheim, 2001; Chap. 8.5., pp 389-406.

10. (a) Hino, K.; Nagai, Y.; Uno, H. Chem. Pharm. Bull. 1987, 35, 2819. (b) Xiao, Z.; Waters, N. C.; Woodard, C. L.; Li, Z.; Li, P.-K. Bioorg. Med. Chem. Lett. 2001, 11, 2875. (c) Dudley, D. A.; Edmunds, J. J. U.S. Patent 6,855,726 B1, 2005.

11. Nitta, Y.; Shibata, A. Chem. Lett. 1998, 27, 161.

12. (a) Shirai, H.; Oda, N. Chem. Pharm. Bull. 1962, 10, 31. (b) Luo, Y.; Tao, F.; Liu, Y.; Li, B.; Zhang, G. Can. J. Chem. 2006, 84, 1620.

13. Hoshina, Y.; Ikegami, S.; Okuyama, A.; Fukui, H.; Inoguchi, K.; Maruyama, T.; Fujimoto, K.; Matsumura, Y.; Aoyama, A.; Harada, T.; Tanaka, H.; Nakamura, T. Bioorg. Med. Chem. Lett. 2005, 15, 217.

14. (a) Bowden, K.; Parkin, D. C. Can. J. Chem. 1968, 46, 3909. (b) Bednowitz, A. L.; Brown, R. G.; Donaruma, L. G.; Hamilton, W. C.; Kropf, R. A.; Southwick, P. L.; Stansfield, R. E. J. Org. Chem. 1974, 39, 3537. (c) Crawford, M.; Moore, G. W. J. Chem. Soc. 1955, 3445. (d) Cadogan, J. I. G.; Duell, E. G.; Inward, P. W. J. Chem. Soc. 1962, 4164. (e) Wassmundt, F. W.; Kiesman, W. F. J. Org. Chem. 1995, 60, 196. (f) Buckles, R. E.; Bellis, M. P.; Coder, Jr. W. D. J. Am. Chem. Soc. 1951, 73, 4972. (g) Jovanović, B. Ž.; Mišić-Vuković, M.; Drmanić, S. Ž.; Čanadi, J. J. J. Mol. Struct. 1997, 410-411, 39.

15. (a) Lewis, T. R.; Pratt, M. G.; Homiller, E. D.; Tullar, B. F.; Archer, S. J. Am. Chem. Soc. 1949, 71, 3749. (b) Wyss, D. F.; Arasappan, A.; Senior, M. M.; Wang, Y.-S.; Beyer, B. M.; Njoroge, F. G.; McCoy, M. A. J. Med. Chem. 2004, 47, 2486. (c) Hino, K.; Nagai, Y.; Uno, H. Chem. Pharm. Bull. 1987, 35, 2819. (d) Zhou, W.; Zhang, L.; Jiao, N. Tetrahedron 2009, 65, 1982. (e) Felpin, F.-X.; Coste, J.; Zakri, C.; Fouquet, E. Chem. Eur. J. 2009, 15, 7238. 